\title{
Comparison of the accuracy of 2D and 3D templating methods for planning primary total hip replacement: a systematic review and meta-analysis
}

\author{
Habeeb Bishi®D, Joshua B V Smith, Vipin Asopa, Richard E Field, \\ Chao Wang and David $\mathrm{H}$ Sochart \\ ${ }^{1}$ South West London Elective Orthopaedic Centre, Epsom General Hospital, Epsom, Surrey, UK
}

Correspondence

should be addressed

to $\mathrm{H}$ Bishi

Email

habeeb.bishi@nhs.net
- There are advocates of both two-dimensional (2D) and three-dimensional (3D) templating methods for planning total hip replacement.

- The aim of this study was to compare the accuracy of implant size prediction when using 2D and 3D templating methods for total hip arthroplasty, as well as to compare the interand intra-observer reliability in order to determine whether currently available methods are sufficiently reliable and reproducible.

- Medline, EMBASE and PubMed were searched to identify studies that compared the accuracy of 2D and 3D templating for total hip replacement.

- Results were screened using the PRISMA flowchart and included studies were assessed for their level of evidence using the Oxford CEBM criteria. Non-randomized trials were critically appraised using the MINORS tool, whilst randomized trials were assessed using the CASP RCT checklist.

- A series of meta-analyses of the data for accuracy were also conducted.

- Ten studies reported that 3D templating is an accurate and reliable method of templating for total hip replacement. Six studies compared 3D templating with 2D templating, all of which concluded that 3D templating was more accurate, with three finding a statistically significant difference.

- The meta-analyses showed that 3D CT templating is the most accurate method.

- This review supports the hypothesis that 3D templating is an accurate and reliable method of preoperative planning, which is more accurate than 2D templating for predicting implant size. However, further research is needed to ascertain the significance of this improved accuracy and whether it will yield any clinical benefit.
Keywords
- 2D templating
- 3D templating
$\rightarrow$ EOS
- hip replacement

\section{Introduction}

Total hip replacement has been the definitive form of treatment for end-stage hip arthritis for several decades and offers significant benefit to these patients by alleviating their pain and improving their mobility. The goal of total hip replacement is to restore the normal anatomy, biomechanics and function of the hip joint (1), which is achieved by replacing the hip with a prosthesis comprising the femoral stem, the acetabular cup and the bearing surfaces. In order to effectively restore normal function of the hip and reduce the rate of intraoperative and postoperative complications, selected implants should be the correct size and implanted in the correct position. One of the ways to ensure optimal size and positioning of the implants is by engaging in thorough preoperative planning, taking into account the patient's age, sex, preoperative diagnosis, mental status, level of activity, medical history and current medical status, expectations from the surgery and life expectancy (2), as well as examination findings and any imaging. The importance of proper preoperative planning has been emphasized by its inclusion in Getting it right first time (GIRFT)'s Best Practice Guidance for Hip Arthroplasty Documentation, which has been published as part of ongoing work to improve patient outcomes and reduce litigation costs following arthroplasty surgery (3).

One of the most important aspects of preoperative planning for total hip replacement is templating, which 
is the process of using radiographs and other forms of imaging, such as computerized tomography (CT) scans, to accurately predict the size and position of implants prior to surgery. Templating has been shown to help predict implants to within one size (4), reducing the risk of periprosthetic fracture (5) and dislocation (6), and helping surgeons to plan the position and depth of insertion of both the femoral and acetabular components, which is a key part of restoring normal hip biomechanics (7). Accurate templating plays a key role in the accurate restoration of hip biomechanics such as femoral offset and the centre of rotation, improving the clinical results of surgery and patient function, whilst helping to reduce complications such as dislocation, as well as decreasing polyethylene wear and increasing implant longevity (8).

In addition to its direct clinical benefits, templating has important medicolegal implications, and demonstrates that a surgeon has thought about and planned a procedure in advance. When correctly performed and documented, templating can therefore help a surgeon's defence against potential claims of negligence, if postoperative complications were to occur (9).

There are a number of different options that can be used to template total hip replacements:

- Two-dimensional (2D) acetate templating, which overlays acetate templates on printed radiographs.

- 2D digital templating, which uses computer software to template implant size and position on digital radiographs.

- Three-dimensional (3D) digital templating, which uses computer software, typically based on CT scans, to template implant size and position but can also be done using EOS $^{\circledast}$ templating software. EOS 3D templating is based on biplanar weight-bearing radiographs obtained in the standing position.

Table 1 Search terms used in HDAS and OVID for Medline.

\begin{tabular}{|c|c|}
\hline $\begin{array}{l}\text { Search } \\
\text { line }\end{array}$ & Search terms \\
\hline 1 & (3D templat* OR 3-D templat* OR three-dimensional templat*).ti,ab \\
\hline 2 & exp "IMAGING, THREE-DIMENSIONAL"/ \\
\hline 3 & (digital templat* OR computer templat* OR software templat*).ti,ab \\
\hline 4 & $\begin{array}{l}\text { (THR OR "total hip replacement*" OR THA OR "total hip arthroplast*" } \\
\text { OR "hip replacement*" OR "hip arthroplast*").ti,ab }\end{array}$ \\
\hline 5 & exp "ARTHROPLASTY, REPLACEMENT, HIP"/ \\
\hline 6 & (1 OR 2 OR 3) \\
\hline 7 & (4 OR 5) \\
\hline 8 & (6 AND 7) \\
\hline 9 & (2D templat* OR 2-D templat* OR two-dimensional templat*).ti,ab \\
\hline 10 & (2D).ti,ab \\
\hline 11 & (3 OR 9 OR 10) \\
\hline 12 & (7 AND 11) \\
\hline 13 & (8 AND 12) \\
\hline
\end{tabular}

Of these different methods, 2D templating is the current standard technique being used in clinical practice and supported by the current literature (10), with both acetate and digital templating being shown to be accurate and reproducible methods of predicting implant size in total hip arthroplasty (11). However, as the hip joint is a 3D structure, 2D templating does have some limitations and can be prone to errors in terms of magnification and patient positioning (12), as well as measurement errors of hip biomechanics such as femoral offset, which can be affected by flexion or rotation (8). These limitations may cause difficulty in selecting the correct size and particularly the position of the implants, especially in complex cases where the normal anatomy of the hip is distorted, e.g. developmental dysplasia of the hip (DDH), Perthes' disease, or following trauma.

The purpose of this systematic review was to compare the accuracy of the existing 2D and 3D templating methods in order to determine which method is more accurate for planning total hip arthroplasty.

\section{Materials and methods}

The review process was conducted according to the Preferred Reporting Items for Systematic Reviews and Meta-Analyses (PRISMA) guidelines.

\section{Search strategy}

HDAS (Medline and EMBASE), OVID (Medline and EMBASE) and PubMed were searched on 23 March 2021 to identify relevant studies in the literature that compared the accuracy of 2D and 3D templating for total hip replacement. A thorough search of the grey literature, including OpenGrey, ClinicalTrials.gov, Cochrane CENTRAL database and medrxiv.org was also conducted. A detailed description of our search strategy is shown in Tables 1, 2 and 3.

Two authors independently considered the search results to select papers for inclusion. Any discrepancies that could not be solved through discussion were decided by a senior reviewer.

\section{PICO and eligibility criteria}

The following PICO criteria were used to select papers:

Population - patients undergoing primary total hip arthroplasty (THA)

Intervention - 3D templating used

Comparison - 2D templating used

Outcome - accuracy of templating (percentage of implant size correctly predicted) 
Table 2 Search terms used in HDAS and OVID for Embase.

\begin{tabular}{|c|c|}
\hline $\begin{array}{l}\text { Search } \\
\text { line }\end{array}$ & Search terms \\
\hline 1 & (3D templat* OR 3-D templat* OR three-dimensional templat*).ti,ab \\
\hline 2 & exp "THREE-DIMENSIONAL IMAGING"/ \\
\hline 3 & (digital templat* OR computer templat* OR software templat*).ti,ab \\
\hline 4 & $\begin{array}{l}\text { (THR OR "total hip replacement*" OR THA OR "total hip arthroplast*" } \\
\text { OR "hip replacement*" OR "hip arthroplast*").ti,ab }\end{array}$ \\
\hline 5 & "TOTAL HIP REPLACEMENT"/ \\
\hline 6 & "HIP REPLACEMENT"/ \\
\hline 7 & "HIP ARTHROPLASTY"/ \\
\hline 8 & (4 OR 5 OR 6 OR 7) \\
\hline 9 & (1 OR 2 OR 3) \\
\hline 10 & (8 AND 9) \\
\hline 11 & (2D templat* OR 2-D templat* OR two-dimensional templat*).ti,ab \\
\hline 12 & (2D).ti,ab \\
\hline 13 & (3 OR 11 OR 12) \\
\hline 14 & (8 AND 13) \\
\hline 15 & (10 AND 14) \\
\hline
\end{tabular}

Inclusion criteria included all papers where 3D templating was used in primary total hip arthroplasty published in the English language. Isolated case reports and papers focusing solely on revision cases were excluded.

\section{Data extraction}

Data were extracted from the included studies using a standardized form, which was incorporated into a Microsoft Excel spreadsheet. The following information was extracted:

1. Study characteristics

2. Patient demographics

3. Implant characteristics

4. Radiographic methods

5. Accuracy of implant size prediction

6. Inter- and intra-observer reliability

7. Main study findings

\section{Quality appraisal}

The level of evidence (LE) was assessed based on previously published criteria by the Oxford Centre for Evidence-Based Medicine (13). The methodological quality and risk of bias in the non-randomized studies was independently assessed by two reviewers using the Methodological Index for Non-Randomized Studies (MINORS) tool (14) and the Critical Appraisal Skills Programme Randomised Control Trials (CASP RCT) checklist was used for the randomized studies (15). The details of the studies involved, including level of evidence, are summarized in Table 4.
Meta-analysis

A series of random-effects meta-analyses were performed for exact and one-size difference in accuracy, respectively. We did not conduct any metaanalysis of the Intraclass Correlation Coefficient (ICC) values as they were not the primary outcome of this article. Considering standard errors or $95 \%$ confidence intervals (Cls) for other secondary outcomes such as ICCs were not typically reported, they are not included in the meta-analyses. DerSimonian-Laird (DL) or profile likelihood ( $\mathrm{PL}$ ) methods were used in the random-effects models as suggested by Kontopantelis and Reeves (16). Heterogeneity was measured using the 12 statistic. Subgroup analyses by templating methods were performed to account for heterogeneity and assess whether there is a statistically significant difference between different templating methods. We also repeated the analysis for each level of surgery complexity (simple, mixed, and complex). The metaanalyses were performed using the 'METAN' package (version 4.02) (17) in Stata 16.1 (StataCorp. 2019. Stata Statistical Software: Release 16. College Station, TX: StataCorp LLC), and the results were presented in forest plots.

\section{Results}

\section{Search results}

An electronic search of the literature revealed a total of 692 studies. After duplicates were removed, 308 studies remained. The records were screened and 12 studies were included in the analysis (Fig. 1). The details of the studies involved, including level of evidence are summarized in Table 4.

\section{Patient demographics}

Across all studies there was a total of 623 hips (587 patients) with a mean age of 61.5 (range: 23 to 91 years). There were 366 women (62.4\%) and 221 men (37.6\%). Hassani et al. (18) did not report the indication for surgery in their study (50 hips), but the indications for surgery when specified were primary osteoarthritis (312 hips, 50.1\%), DDH/CDH (205 hips, 32.9\%), osteonecrosis (40 hips, 6.4\%), ankylosing spondylitis (9 hips, 1.4\%), post-traumatic osteoarthritis ( 3 hips, $0.5 \%$ ), rheumatoid arthritis (2 hips, $0.3 \%$ ), Perthes' disease (1 hip, 0.2\%)

Table 3 Search query used in PubMed.

\begin{tabular}{ll}
\hline Search line & $\begin{array}{l}\text { Search query } \\
1\end{array}$ \\
$\begin{array}{c}(((((\text { THR OR "total hip replacement*" OR THA OR "total hip arthroplast*" OR "hip replacement*" OR "hip arthroplast*" ) OR (hip replacement, } \\
\text { total[MeSH Terms])) OR (hip arthroplasty[MeSH Terms])) AND (3d templat*)) OR (three dimensional[MeSH Terms]) }\end{array}$
\end{tabular}


Table 4 Study characteristics and level of evidence.

\begin{tabular}{|c|c|c|c|}
\hline Reference & Year & Study design & Country \\
\hline Brenneis et al. (12) & 2021 & RCT & Germany \\
\hline Hassani et al. (18) & 2014 & CS & Switzerland \\
\hline Huo et al. (19) & 2021 & CS & China \\
\hline Inoue et al. (20) & 2015 & CS & Japan \\
\hline Knafo et al. (21) & 2019 & CS & France \\
\hline Mainard et al. (22) & 2017 & CC & France \\
\hline Sariali et al. (23) & 2012 & LPPRT & France \\
\hline Schiffner et al. (10) & 2019 & CS & Germany \\
\hline Viceconti et al. (24) & 2003 & CS & Italy \\
\hline Wako et al. (25) & 2018 & CS & Japan \\
\hline Wu et al. (26) & 2018 & CS & China \\
\hline Zeng et al. (27) & 2014 & CS & China \\
\hline
\end{tabular}

\begin{tabular}{|c|c|}
\hline \multicolumn{2}{|c|}{ Number of } \\
\hline Hips & Patients \\
\hline 51 & 51 \\
\hline 50 & 50 \\
\hline 59 & 53 \\
\hline 65 & 57 \\
\hline 33 & 33 \\
\hline 31 & 31 \\
\hline $60^{*}$ & 60 \\
\hline 116 & 116 \\
\hline 29 & 29 \\
\hline 60 & 46 \\
\hline 49 & 41 \\
\hline 20 & 20 \\
\hline
\end{tabular}

$\frac{\text { Indication for surgery }}{\text { Unilateral hip OA }}$

Not reported

DDH: 16; OA: 16; Osteonecrosis: 16; Ankylosing spondylitis: 9; RA: 2

DDH

Primary OA

Primary OA: 30; Trauma: 1

Primary OA

Primary OA

CDH: 19; Primary OA: 6; Post-traumatic OA: 2; Secondary OA/Perthes:

1; Revision: 1

OA:36; Osteonecrosis : 24

DDH

DDH

$* 2 \times 30$.

$\mathrm{OA}$, osteoarthritis; $\mathrm{CDH}$, Congenital dysplasia of the hip; DDH, Developmental dysplasia of the hip; RA, Rheumatoid arthritis; RCT, randomized control trial; CC, case-control; CS, case series; LPPRT, Low-powered prospective randomised trial; LOE, level of evidence.

and revision of an infected femoral stem (1 hip, 0.2\%). A detailed breakdown of the patient demographics of each study is shown in Table 5.

\section{Implant characteristics}

Uncemented implants were used in 11 of the 12 studies included (10, 12, 18, 19, 20, 21, 23, 24, 25, $26,27)$, with the remaining study failing to specifically document the mode of fixation used (22). Eight studies documented the design of both the cup and the stem that were implanted $(10,12,19,20,21,22,24,25)$, two reported the stem used but not the cup $(18,23)$ and the remaining two reported the cup used but not the stem (Table 5) $(26,27)$.

\section{Radiographic methods}

Nine of the studies used CT-based 3D templating (10, $18,19,20,23,24,25,26,27)$, whilst the remaining three used EOS-based 3D templating software $(12,21$, 23). EOS 3D templating uses radiographs obtained by the EOS ${ }^{\circledR}$ imaging system. This imaging system rests on the simultaneous acquisition, in the standing, weightbearing position, of two orthogonal radiographic images using slot-scanning technology (21). For comparison, four of the studies used 2D digital templating $(10,12,19$, 23 ) and three of the studies used $2 \mathrm{D}$ acetate templating $(22,24,27)$. A full breakdown, with details of how the $2 \mathrm{D}$ templating studies corrected for magnification is shown in Table 6.

\section{Accuracy of implant size prediction}

All 12 studies included $(10,12,18,19,20,21,22,23,24,25$, 26,27 ) used $3 \mathrm{D}$ templating (EOS or CT-based templating software), and seven of them $(10,12,19,22,23,24,26)$ used both 2D (digital or acetate) and 3D templating (EOS or CT-based templating software).

Exact prediction of the implant size using 2D templating methods ranged between $25 \%$ and $85.7 \%$ for the cup and between $32 \%$ and $49.15 \%$ for the stem. When using 3D templating methods this ranged between $40 \%$ and $98 \%$ for the cup and between $34 \%$ and $100 \%$ for the stem.

When predicting to within one size of the correct implant the accuracy of 2D templating methods ranged between $45 \%$ and $89.3 \%$ for the cup and between $60.7 \%$ and $83.6 \%$ for the stem. When using $3 \mathrm{D}$ templating

\section{PxISMEI PRISMA 2009 Flow Diagram}

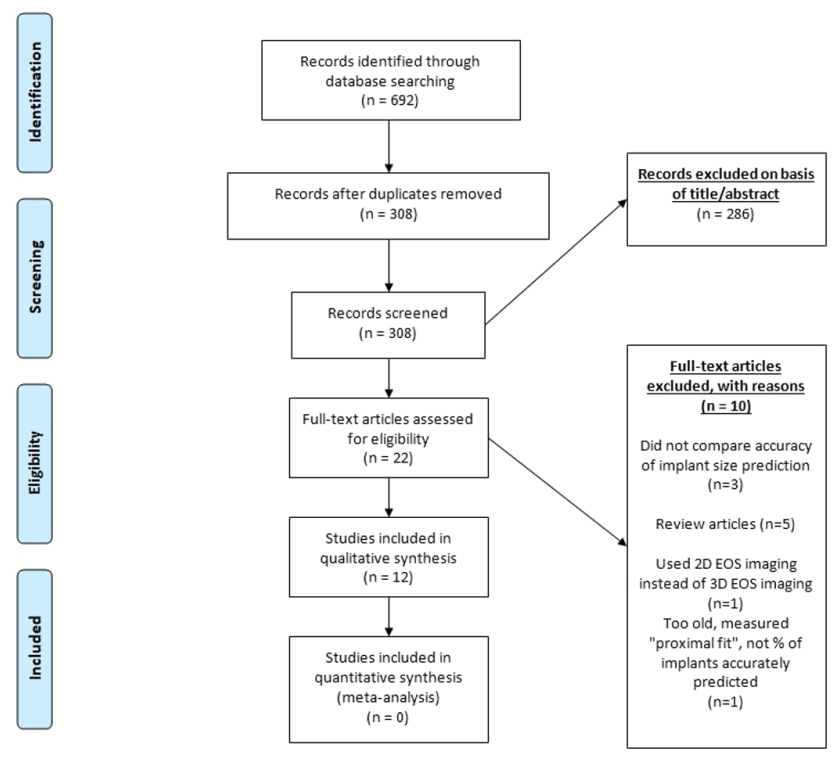

\section{Figure 1}

Preferred Reporting Items for Systematic Reviews and MetaAnalyses (PRISMA) flowchart. 

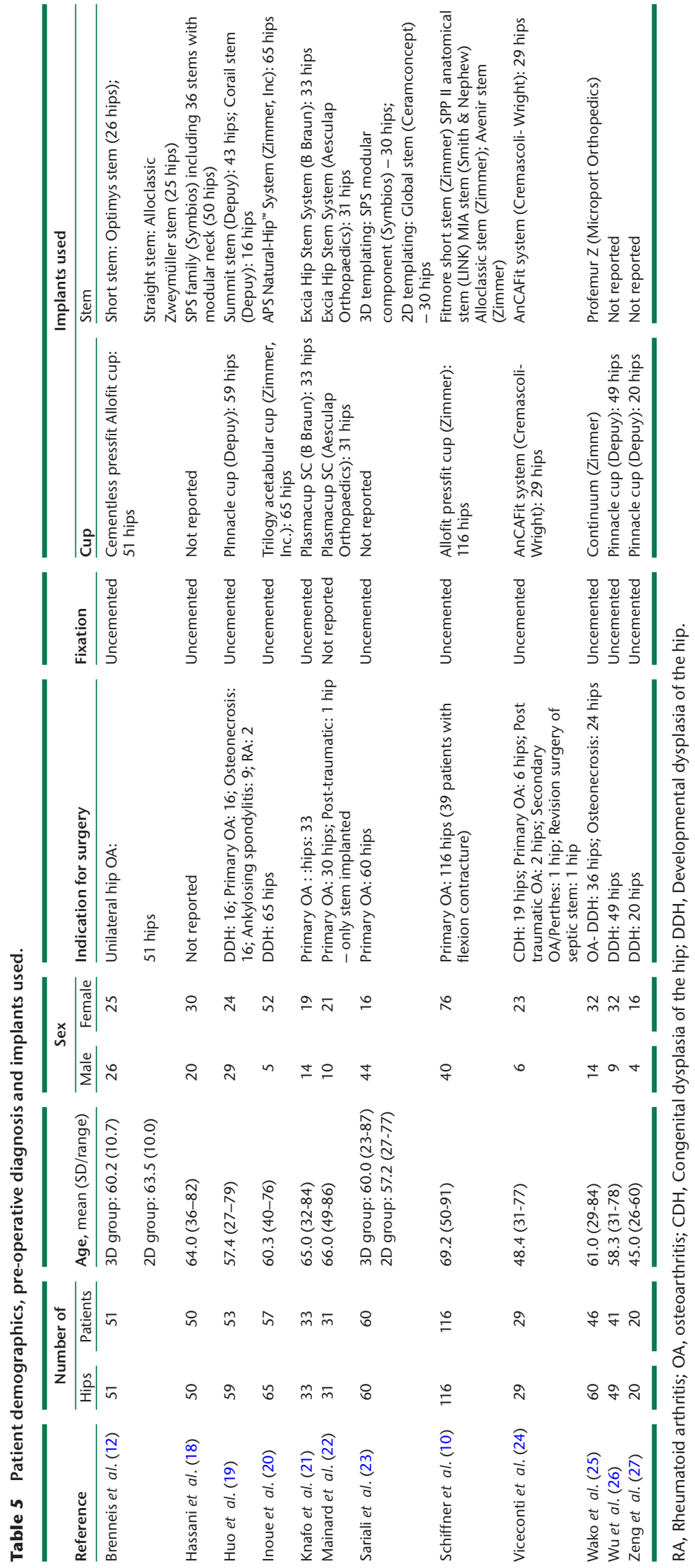
Table 6 Patient numbers and templating methodology.

\begin{tabular}{|c|c|c|c|}
\hline Study & Hips, $n$ & Patients, $n$ & 2D templating method \\
\hline Brenneis et al. (12) & 51 & 51 & $\begin{array}{l}\text { TraumaCad }(2 \mathrm{D}) \text { planning software } \\
\text { 2D digital radiographs }\end{array}$ \\
\hline Hassani et al. (18) & 50 & 50 & $\mathrm{~N} / \mathrm{A}$ \\
\hline Huo et al. (19) & 59 & 53 & $\begin{array}{l}\text { 2D digital template (Smart joint, } \\
\text { Depuy Synthes) superimposed on } \\
\text { AP pelvic radiograph }\end{array}$ \\
\hline Inoue et al. (20) & 65 & 57 & $\mathrm{~N} / \mathrm{A}$ \\
\hline Knafo et al. (21) & 33 & 33 & N/A \\
\hline Mainard et al. (22) & 31 & 31 & 2D conventional acetate templating \\
\hline Sariali et al. (23) & 60 & 60 & $\begin{array}{l}\text { Imagika software } \\
\text { 2D digital templating }\end{array}$ \\
\hline Schiffner et al. (10) & 116 & 116 & $\begin{array}{l}\text { HECTEC 2D digital templating } \\
\text { software }\end{array}$ \\
\hline Viceconti et al. (24) & 29 & 29 & 2D acetate templating \\
\hline Wako et al. (25) & 60 & 46 & $\mathrm{~N} / \mathrm{A}$ \\
\hline Wu et al. (26) & 49 & 41 & $\mathrm{~N} / \mathrm{A}$ \\
\hline Zeng et al. (27) & 20 & 20 & 2D acetate templating \\
\hline
\end{tabular}

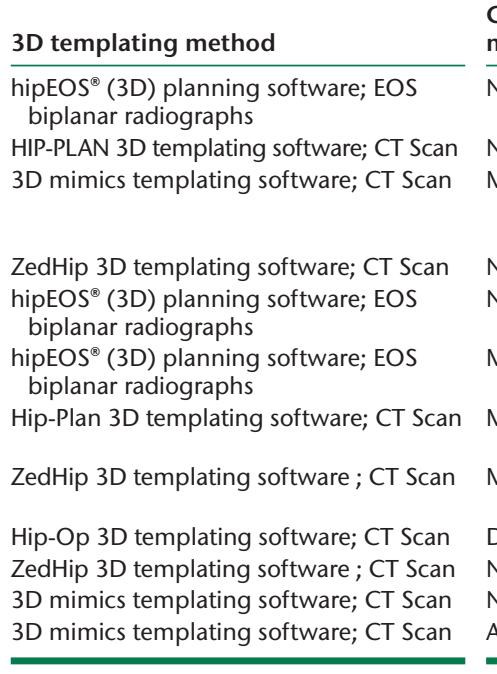

\begin{tabular}{l} 
Correction for \\
magnification (2D) \\
\hline N/A \\
N/A \\
Marker ball (38mm) for 2D \\
radiographs \\
N/A \\
N/A \\
Magnification of 1.15 was used \\
for the 2D radiographs \\
Magnification of 1.15 was used \\
for the 2D radiogrpahs \\
Marker ball (32mm) for $2 D$ \\
radiographs \\
Did not report on magnification \\
N/A \\
N/A \\
Average 20\% magnification
\end{tabular}

methods this ranged between $86.2 \%$ and $100 \%$ for the cup and between $84 \%$ and $98 \%$ for the stem.

A full breakdown of the accuracy of implant size prediction is given in Tables 7, 8, 9 and 10.

\section{Inter-observer and intra-observer reliability}

Five of the studies commented on the inter-observer and intra-observer reliability of the templating methods used. The Intraclass Correlation Coefficient (ICC) was used to calculate the inter-observer and intra-observer reliability, with an ICC above a prescribed threshold of 0.70 being considered statistically consistent for agreement (11).

The ICC was above 0.70 for three of the templating methods used, indicating that they were sufficiently reliable and reproducible. Only one study (20) reported an ICC of less than $0.70(0.60)$ for inter-observer reliability of stem size prediction using 3D templating.

Brenneis et al. (12) found that inter-observer and intra-observer reliability was higher in 3D templating for predicting both cup and stem sizes, with Mainard et al.
(22) reporting that the inter-observer reliability was higher in 3D templating for the prediction of cup size but higher in 2D templating for the prediction of stem size.

A full breakdown of the ICCs calculated for each study can be seen in Tables 11, 12, 13 and 14 .

\section{Study findings}

Ten of the 12 studies $(10,12,18,20,21,22,23,24,25$, 27 ) concluded that $3 \mathrm{D}$ templating was an accurate and reliable method of preoperative planning for total hip arthroplasty. The remaining studies $(19,25)$ did not comment on this; for one study (19), the primary aim was to investigate the accuracy of and time taken for $\mathrm{Al}$ hip templating software compared to existing 2D and 3D methods, whilst the primary aim in the other study (25) was only to assess the inter- and intra-observer reliability of 3D templating software.

Six of the 12 studies $(10,12,22,23,24,27)$ compared the accuracy of implant size prediction between 2D and

Table 7 Accuracy of cup size prediction using 2D templating methods.

\begin{tabular}{|c|c|c|c|c|c|c|c|}
\hline \multirow[b]{2}{*}{ Study } & \multicolumn{2}{|c|}{ Number of } & \multirow[b]{2}{*}{ Pre-operative diagnosis } & \multirow[b]{2}{*}{ Fixation } & \multirow[b]{2}{*}{ Modality } & \multicolumn{2}{|c|}{$\begin{array}{l}\text { Accuracy of cup size } \\
\text { prediction }\end{array}$} \\
\hline & Hips & Patients & & & & EXACT & +/- ONE SIZE \\
\hline Brenneis et al. (12) & 23 & 23 & Unilateral hip OA & Uncemented & 2D digital templating & $85.7 \%$ & $89.3 \%$ \\
\hline Huo et al. (19) & 59 & 53 & $\begin{array}{l}\text { DDH: 16; Primary OA: 16; Osteonecrosis: 16; } \\
\text { Ankylosing spondylitis: 9; RA: } 2\end{array}$ & Uncemented & 2D digital templating & $40.68 \%$ & $77.97 \%$ \\
\hline Mainard et al. (22) & 31 & 31 & Primary OA Post-traumatic : 1 & Not reported & 2D acetate templating & $40 \%$ & $87 \%$ \\
\hline Sariali et al. (23) & 60 & 60 & Primary OA & Uncemented & $\begin{array}{l}\text { 2D digital templating } \\
\text { on plain xrays }\end{array}$ & $43 \%$ & Not reported \\
\hline Schiffner et al. (10) & 116 & 116 & Primary OA & Uncemented & 2D digital templating & $44.8 \%$ & $80.2 \%$ \\
\hline Viceconti et al. (24) & 29 & 29 & $\begin{array}{l}\text { CDH: 19; Primary OA: } 6 \text {, Post-traumatic OA: 2; } \\
\text { Secondary OA/Perthes: 1; Revision: } 1\end{array}$ & Uncemented & 2D acetate templating & $41 \%$ & $69 \%$ \\
\hline Zeng et al. (27) & 20 & 20 & $\mathrm{DDH}$ & Uncemented & 2D acetate templating & $25 \%$ & $45 \%$ \\
\hline
\end{tabular}

OA, osteoarthritis; $\mathrm{CDH}$, Congenital dysplasia of the hip; DDH, Developmental dysplasia of the hip; RA, Rheumatoid arthritis. 
Table 8 Accuracy of stem size prediction using 2D templating methods.

\begin{tabular}{|c|c|c|c|c|c|c|c|}
\hline \multirow[b]{2}{*}{ Study } & \multicolumn{2}{|c|}{ Number of } & \multirow[b]{2}{*}{ Pre-operative diagnosis } & \multirow[b]{2}{*}{ Fixation } & \multirow[b]{2}{*}{ Modality } & \multicolumn{2}{|c|}{$\begin{array}{l}\text { Accuracy of stem size } \\
\text { prediction }\end{array}$} \\
\hline & Hips & Patients & & & & EXACT & $+/-$ ONE SIZE \\
\hline Brenneis et al. (12) & 23 & 23 & Unilateral hip OA & Uncemented & 2D digital templating & $35.7 \%$ & $60.7 \%$ \\
\hline Huo et al. (19) & 59 & 53 & $\begin{array}{l}\text { DDH: 16; Primary OA: 16; OA: } 16 \text {; } \\
\text { Ankylosing spondylitis: 9; RA: } 2\end{array}$ & Uncemented & 2D digital templating & $49.15 \%$ & $74.58 \%$ \\
\hline Mainard et al. (22) & 31 & 31 & Primary OA; Post-traumatic: 1 & Not reported & 2D acetate templating & $32 \%$ & $68 \%$ \\
\hline Sariali et al. (23) & 60 & 60 & Primary OA & Uncemented & 2D digital templating on plain xrays & $43 \%$ & NR \\
\hline Schiffner et al. (10) & 116 & 116 & Primary OA & Uncemented & 2D digital templating & $45.7 \%$ & $83.6 \%$ \\
\hline Viceconti et al. (24) & 29 & 29 & $\begin{array}{l}\text { CDH: 19; Primary OA: } 6 \text {; } \\
\text { Post traumatic OA: } 2 \text {; } \\
\text { Secondary OA/Perthes: } 1 \text {; } \\
\text { Revision: } 1\end{array}$ & Uncemented & 2D acetate templating & $34 \%$ & $83 \%$ \\
\hline Zeng et al. (27) & 20 & 20 & $\mathrm{DDH}$ & Uncemented & 2D acetate templating & NR & NR \\
\hline
\end{tabular}

NR, Not reported; OA, osteoarthritis; $\mathrm{CDH}$, Congenital dysplasia of the hip; DDH, Developmental dysplasia of the hip.

3D templating, with four of the six comparing CT-based 3D templating with $2 \mathrm{D}$ templating (digital and acetate) $(10,12,19,23)$.

Schiffner et al. (10) reported that 3D templating was an accurate, reproducible process, which was significantly more accurate than 2D templating for both cup and stem size prediction. Sariali et al. (23) reported that CT-based 3D templating had a higher accuracy than conventional 2D templating for total hip arthroplasty planning, but did not comment on the statistical significance. Viceconti et al. (24) reported that the 3D templating software was more accurate than conventional 2D templating, especially for predicting the cup size, but did not comment on the statistical significance, and Zeng et al. (27) reported that 3D templating was more accurate than 2D acetate templating, especially when deformed anatomies were involved but again did not comment on the statistical significance.

The remaining two studies compared EOS 3D templating with 2D templating (digital and acetate). Brenneis et al. (12) reported that EOS 3D planning was significantly more accurate for predicting short stems, but there was no significant difference in the planning accuracy of the cup or of straight stems. Mainard et al. (22) reported that EOS 3D templating was significantly more accurate for stem size prediction, but that although 3D templating was also more accurate for cup size prediction, this difference was not statistically significant.

\section{Meta-analysis}

We conducted a series of meta-analyses of the assembled data for accuracy of implant size prediction. For proportion of implants predicted exactly (Fig. 2), 3D CT templating was most accurate (0.79), then $2 \mathrm{D}$ digital $(0.48)$, then $3 \mathrm{D}$ EOS (0.43), then $2 \mathrm{D}$ acetate (0.35). There was a statistically significant difference between the four groups $(p<0.001)$.

For proportion of implants predicted within one size (Fig. 3), 3D CT and 3D EOS templating were the most accurate (0.96), then 2D digital templating (0.80), then $2 \mathrm{D}$ acetate templating (0.72). There was a statistically significant difference between the four groups $(p<0.001)$.

Table 9 Accuracy of cup size prediction using 3D templating methods.

\begin{tabular}{|c|c|c|c|}
\hline \multirow[b]{2}{*}{ Study } & \multicolumn{2}{|c|}{ Number of } & \multirow[b]{2}{*}{ Pre-operative diagnosis } \\
\hline & Hips & Patients & \\
\hline Brenneis et al. (12) & 28 & 28 & Unilateral hip OA \\
\hline Hassani et al. (18) & 50 & 50 & NR \\
\hline Huo et al. (19) & 59 & 53 & $\begin{array}{l}\text { DDH: 16; Primary OA: 16; Osteonecrosis: } \\
\text { 16; Ankylosing spondylitis: 9; RA: } 2\end{array}$ \\
\hline Inoue et al. (20) & 65 & 57 & $\mathrm{DDH}$ \\
\hline Knafo et al. (21) & 33 & 33 & Primary OA \\
\hline Mainard et al. (22) & 31 & 31 & Primary OA: 30; Post-traumatic: 1 \\
\hline Sariali et al. (23) & 60 & 60 & Primary OA \\
\hline Schiffner et al. (10) & 116 & 116 & Primary OA: $39^{*}$ \\
\hline Viceconti et al. (24) & 29 & 29 & $\begin{array}{l}\text { CDH: 19; Primary OA: } 6 \text {, Post traumatic } \\
\text { OA : } 2 \text {; Secondary OA/Perthes: } 1 \text {; } \\
\text { Revision: } 1\end{array}$ \\
\hline Wu et al. (26) & 49 & 41 & $\mathrm{DDH}$ \\
\hline Zeng et al. (27) & 20 & 20 & $\mathrm{DDH}$ \\
\hline
\end{tabular}

\begin{tabular}{|c|c|}
\hline Fixation & Modality \\
\hline Uncemented & EOS 3D software \\
\hline Uncemented & CT based 3D templating software \\
\hline Uncemented & CT based 3D mimics software \\
\hline Uncemented & CT based 3D templating software \\
\hline Uncemented & EOS 3D software \\
\hline Not reported & EOS 3D software \\
\hline Uncemented & CT based 3D software \\
\hline Uncemented & $\mathrm{CT}$ based 3D software \\
\hline Uncemented & $\mathrm{CT}$ based 3D software \\
\hline Uncemented & CT based 3D templating software \\
\hline Uncemented & CT based 3D software \\
\hline
\end{tabular}

\begin{tabular}{|c|c|}
\hline \multicolumn{2}{|c|}{$\begin{array}{l}\text { Accuracy of cup size } \\
\text { prediction }\end{array}$} \\
\hline EXACT & $+/-$ ONE SIZE \\
\hline $43.5 \%$ & $100 \%$ \\
\hline $94 \%$ & NR \\
\hline $71.19 \%$ & $93.22 \%$ \\
\hline $98 \%$ & $100 \%$ \\
\hline $55 \%$ & $100 \%$ \\
\hline $40 \%$ & $93 \%$ \\
\hline $96 \%$ & NR \\
\hline $56.9 \%$ & $86.2 \%$ \\
\hline $66 \%$ & $93 \%$ \\
\hline $71 \%$ & $100 \%$ \\
\hline $70 \%$ & $100 \%$ \\
\hline
\end{tabular}

* patients with flexion contracture.

$\mathrm{Nr}$, not reported; OA, osteoarthritis; $\mathrm{CDH}$, Congenital dysplasia of the hip; DDH, Developmental dysplasia of the hip; RA, Rheumatoid arthritis. 
Table 10 Accuracy of stem size prediction using 3D templating methods.

\begin{tabular}{|c|c|c|c|c|c|c|c|}
\hline \multirow[b]{2}{*}{ Study } & \multicolumn{2}{|c|}{ Number of } & \multirow[b]{2}{*}{ Pre-operative diagnosis } & \multirow[b]{2}{*}{ Fixation } & \multirow[b]{2}{*}{ Modality } & \multicolumn{2}{|c|}{$\begin{array}{l}\text { Accuracy of implants } \\
\text { size prediction }\end{array}$} \\
\hline & Hips & Patients & & & & $\overline{\text { EXACT }}$ & +/- ONE SIZE \\
\hline Brenneis et al. (12) & 28 & 28 & Unilateral hip OA & Uncemented & EOS 3D software & $34.8 \%$ & $91.3 \%$ \\
\hline Huo et al. (19) & 59 & 53 & $\begin{array}{l}\text { DDH: 16; Primary OA: 16; Osteonecrosis: } \\
\text { 16; Ankylosing spondylitis: 9; RA: } 2\end{array}$ & Uncemented & $\mathrm{CT}$ based 3D mimics software & $76.27 \%$ & $93.22 \%$ \\
\hline Inoue et al. (20) & 65 & 57 & $\mathrm{DDH}$ & Uncemented & $\mathrm{CT}$ based 3D templating software & $65 \%$ & $98 \%$ \\
\hline Knafo et al. (21) & 33 & 33 & Primary OA & Uncemented & EOS 3D software & $48 \%$ & $94 \%$ \\
\hline Schiffner et al. (10) & 116 & 116 & Primary OA: $39^{*}$ & Uncemented & CT based 3D software & $58.6 \%$ & $94 \%$ \\
\hline Viceconti et al. (24) & 29 & 29 & $\begin{array}{l}\text { CDH: 19; Primary OA: 6, Post traumatic OA: } \\
\text { 2; Secondary OA/Perthes: } 1 \text {; Revision: } 1\end{array}$ & Uncemented & CT based 3D software & $52 \%$ & $86 \%$ \\
\hline Wu et al. (26) & 49 & 41 & DDH & Uncemented & $\mathrm{CT}$ based 3D templating software & NR & NR \\
\hline Zeng et al. (27) & 20 & 20 & $\mathrm{DDH}$ & Uncemented & CT based 3D software & NR & NR \\
\hline
\end{tabular}

We also conducted a subgroup analysis based on the complexity of the cases. The papers were divided into simple, mixed and complex based on the preoperative diagnosis/indication for surgery.

For proportion of implants predicted exactly for simple cases (Fig. 4), 3D CT templating was most accurate (0.78), then 2D digital (0.50), then 3D EOS (0.43), then $2 \mathrm{D}$ acetate $(0.36)$. There was a statistically significant difference between the four groups $(P=0.002)$. For proportion of implants predicted within one size for simple cases (Fig. 5), 3D EOS templating was most accurate (0.96), then 3D CT (0.90), then 2D digital (0.81), then $2 \mathrm{D}$ acetate $(0.78)$. There was a statistically significant difference between the four groups $(P=0.002)$. For proportion of implants predicted exactly for mixed cases (Fig. 6), 3D CT templating was most accurate (0.68), then $2 \mathrm{D}$ digital $(0.45)$, then $2 \mathrm{D}$ acetate $(0.37)$. There was a statistically significant difference between the three groups $(P<0.001)$. For proportion of implants predicted within one size for mixed cases (Fig. 7), 3D CT templating was most accurate (0.93), then $2 \mathrm{D}$ acetate $(0.77)$, then $2 \mathrm{D}$ digital (0.76). There was a statistically significant difference between all three groups $(P<0.001)$. For prediction of implant size for complex cases, only 3D CT templating and $2 \mathrm{D}$ acetate templating could be compared from the assembled data. 3D CT templating (0.77) was significantly more accurate than $2 \mathrm{D}$ acetate templating $(0.25)$ for both exact implant size prediction $(P<0.001)$ (Fig. 8$)$ and implant size prediction within one size (3D CT $=1.00,2 \mathrm{D}$ acetate $=0.45)(P<0.001)$ (Fig. 9).

There was high relative heterogeneity within some of the subgroups analysed, which may be explained by other unobserved factors, such as a difference in the preoperative diagnosis and complexity of the cases being templated or differing levels of experience amongst the templating surgeons.

\section{Discussion}

It has long been established that 2D preoperative templating for THA by either acetate or digital means is relatively reliable and reproducible. However, in order to ensure the best outcomes for patients, more recently developed 3D templating methods should be compared to see whether they confer any benefit over existing 2D methods.

The results presented by the studies in this review confirm that 3D templating is more accurate than 2D templating for planning total hip arthroplasty in terms of implant size prediction, and have also demonstrated that 3D templating methods are sufficiently reliable and reproducible when compared to $2 \mathrm{D}$ methods. The results from the meta-analysis also support this hypothesis but should be interpreted with caution, given the high heterogeneity amongst the subgroups analysed. Despite these findings, 2D templating remains the current

Table 11 Inter- and intra- observer reliability of cup size prediction using 2D templating methods.

\begin{tabular}{|c|c|c|c|c|c|}
\hline \multirow[b]{2}{*}{ Study } & \multicolumn{2}{|c|}{ Number of } & \multirow[b]{2}{*}{ Templating method } & \multicolumn{2}{|r|}{ Observer reliability, ICC } \\
\hline & Hips & Patients & & Inter & Intra \\
\hline Brenneis et al. (12) & 51 & 51 & 2D digital templating & $0.843(0.690-0.924)$ & $\begin{array}{l}\text { Observer 1: } 0.836(0.642-0.925) \text {; } \\
\text { Observer 2: } 0.956(0.884-0.982)\end{array}$ \\
\hline Mainard et al. (22) & 31 & 31 & 2D acetate templating & 0.71 & Not calculated \\
\hline Zeng et al. (27) & 20 & 20 & 2D acetate templating & Not calculated & Not calculated \\
\hline
\end{tabular}

ICC, intraclass correlation co-efficient. 
Table 12 Inter- and intra- observer reliability of stem size prediction using 2D templating methods.

\begin{tabular}{|c|c|c|c|}
\hline \multirow[b]{2}{*}{ Study } & \multicolumn{2}{|c|}{ Number of } & \multirow[b]{2}{*}{ Templating method } \\
\hline & Hips & Patients & \\
\hline Brenneis et al. (12) & 51 & 51 & 2D digital templating \\
\hline Mainard et al. (22) & 31 & 31 & 2D acetate templating \\
\hline Zeng et al. (27) & 20 & 20 & 2D acetate templating \\
\hline
\end{tabular}

\begin{tabular}{|c|c|}
\hline \multicolumn{2}{|c|}{ Observer reliability, ICC } \\
\hline Inter & Intra \\
\hline $0.835(0.314-0.944)$ & $\begin{array}{l}\text { Observer 1: } 0.877(0.720-0.945) \text {; } \\
\text { Observer 2: } 0.873(0.736-0.940)\end{array}$ \\
\hline 0.91 & Not calculated \\
\hline Not calculated & Not calculated \\
\hline
\end{tabular}

standard for planning THA and may remain so for the foreseeable future but, given the superior accuracy of $3 \mathrm{D}$ templating, it is important that we question why this is the case.

Firstly, when comparing 2D and 3D templating methods, it is necessary to consider whether any differences in accuracy are statistically significant. Of the six studies $(10,12,22,23,24,27)$ that directly compared $2 \mathrm{D}$ and $3 \mathrm{D}$ templating methods, only three $(10,12,22)$ commented on the statistical significance of any difference in accuracy. Further research in this area will need to comment on the statistical significance of any improved accuracy.

Moreover, even if 3D templating does provide a significant improvement with regard to the accuracy of implant size prediction, it is difficult to determine whether or not this will yield any clinical benefit. One of the most obvious reasons that 3D templating is not widely used is the relative difficulty in accessing 3D templating, when compared to 2D templating. It is far easier and less expensive to arrange plain radiographs in a hospital than CT scans and even after the images are obtained, the software needed to perform 3D templating is not typically available in most hospitals.

Although EOS templating software, which is a relatively new technology that uses biplanar weight-bearing radiographs to obtain full-length $3 \mathrm{D}$ images, has been mentioned in three of the studies in this review $(12,21$, $22)$, the majority of $3 \mathrm{D}$ templating is currently performed using CT images, which may prompt concerns regarding an associated increased radiation dose and expense. Huppertz et al. (28) reported that the mean effective radiation dose of $4.0 \mathrm{mSv}$ necessary for an appropriate CT scan of the pelvis was at least $30 \%$ higher than that of conventional pelvic radiographs (without taking repeated exposure into account).

Despite the increased accuracy that 3D templating offers, it is still unclear whether the higher radiation dose is justifiable for the vast majority of routine primary THA as there is not yet evidence suggesting an improvement of outcomes from this approach. However, the introduction and development of reduced-dose CT protocols is something that may address this issue whilst still maintaining sufficient image quality to be used for templating (29).

In addition to the increased radiation associated with CT-based 3D templating, another factor that may have prevented the uptake of 3D templating is the increased imaging and software costs that are associated with 3D templating in addition to the direct costs of preoperative CT, which have been reported to be approximately 53-116 euro per patient (30).

As well as predicting implant size more accurately, 3D templating can also help the surgeon to more accurately visualize the anatomy of the pelvis (a 3D structure) which can aid in planning, decision making and anticipation of intraoperative complications. The extent to which orthopaedic surgeons routinely conceptualize their operations in three dimensions, or indeed wish to do so, is debatable, although 3D templating would certainly help with this process.

Despite all of the information that CT-based 3D planning can provide, one of its most obvious limitations is that the CT scan is performed with the patient supine, as opposed to 2D templating which can use weightbearing anteroposterior (AP) plain radiographs as well as lateral ones. It can therefore be argued that, by using this method of 3D templating, one could potentially lose

Table 13 Inter- and intra-observer reliability of cup size prediction using 3D templating methods.

\begin{tabular}{|c|c|c|c|c|c|}
\hline \multirow[b]{2}{*}{ Study } & \multicolumn{2}{|c|}{ Number of } & \multirow[b]{2}{*}{ Templating method } & \multicolumn{2}{|c|}{ Observer reliability, ICC } \\
\hline & Hips & Patients & & Inter & Intra \\
\hline Brenneis et al. (12) & 51 & 51 & EOS 3D templating & $0.918(0.780-0.967)$ & $\begin{array}{l}\text { Observer 1: } 0.929(0.842-0.969) \\
\text { Observer 2: } 0.924(0.830-0.967)\end{array}$ \\
\hline Inoue et al. (20) & 65 & 57 & $\mathrm{CT}$ based 3D templating & 0.80 & 0.95 \\
\hline Mainard et al. (22) & 31 & 31 & EOS 3D templating & 0.84 & $\begin{array}{l}\text { Operator 1: } 0.91 \text {; } \\
\text { Operator 2: } 0.96\end{array}$ \\
\hline Wako et al. (25) & 60 & 46 & $\mathrm{CT}$ based $3 \mathrm{D}$ templating & 0.907 & 0.965 \\
\hline Zeng et al. (27) & 20 & 20 & $\mathrm{CT}$ based $3 \mathrm{D}$ templating & 0.87 & 0.81 \\
\hline
\end{tabular}

ICC, intraclass correlation co-efficient. 
Table 14 Inter- and intra- observer reliability of stem size prediction using 3D templating methods.

\begin{tabular}{|c|c|c|c|}
\hline \multirow[b]{2}{*}{ Study } & \multicolumn{2}{|c|}{ Number of } & \multirow[b]{2}{*}{ Templating method } \\
\hline & Hips & Patients & \\
\hline Brenneis et al. (12) & 51 & 51 & EOS 3D templating \\
\hline Inoue et al. (20) & 65 & 57 & $\mathrm{CT}$ based 3D templating \\
\hline Mainard et al. (22) & 31 & 31 & EOS 3D templating \\
\hline Wako et al. (25) & 60 & 46 & $\mathrm{CT}$ based 3D templating \\
\hline Zeng et al. (27) & 20 & 20 & $\mathrm{CT}$ based 3D templating \\
\hline
\end{tabular}

\begin{tabular}{|c|c|}
\hline \multicolumn{2}{|c|}{ Observer reliability, ICC } \\
\hline Inter & Intra \\
\hline $0.906(0.794-0.959)$ & $\begin{array}{l}\text { Surgeon 1: } 0.967(0.913-0.993) \text {; } \\
\text { Surgeon 2: } 0.940(0.865-0.967)\end{array}$ \\
\hline 0.60 & 0.95 \\
\hline 0.88 & $\begin{array}{l}\text { Operator 1: } 0.88 \\
\text { Operator 2: } 0.92\end{array}$ \\
\hline 0.944 & 0.972 \\
\hline Not calculated & Not calculated \\
\hline
\end{tabular}

crucial information about the spino-pelvic relationship in the standing position, which may have implications for the outcome of surgery and the risk of dislocation. However, the significance of this remains unknown.

Sacral slope, pelvic tilt and lumbar lordosis are spinopelvic parameters that are key to understanding the spinopelvic relationship and are 'functional parameters'. This means that their value changes with body position (31), which must be taken into account when planning total

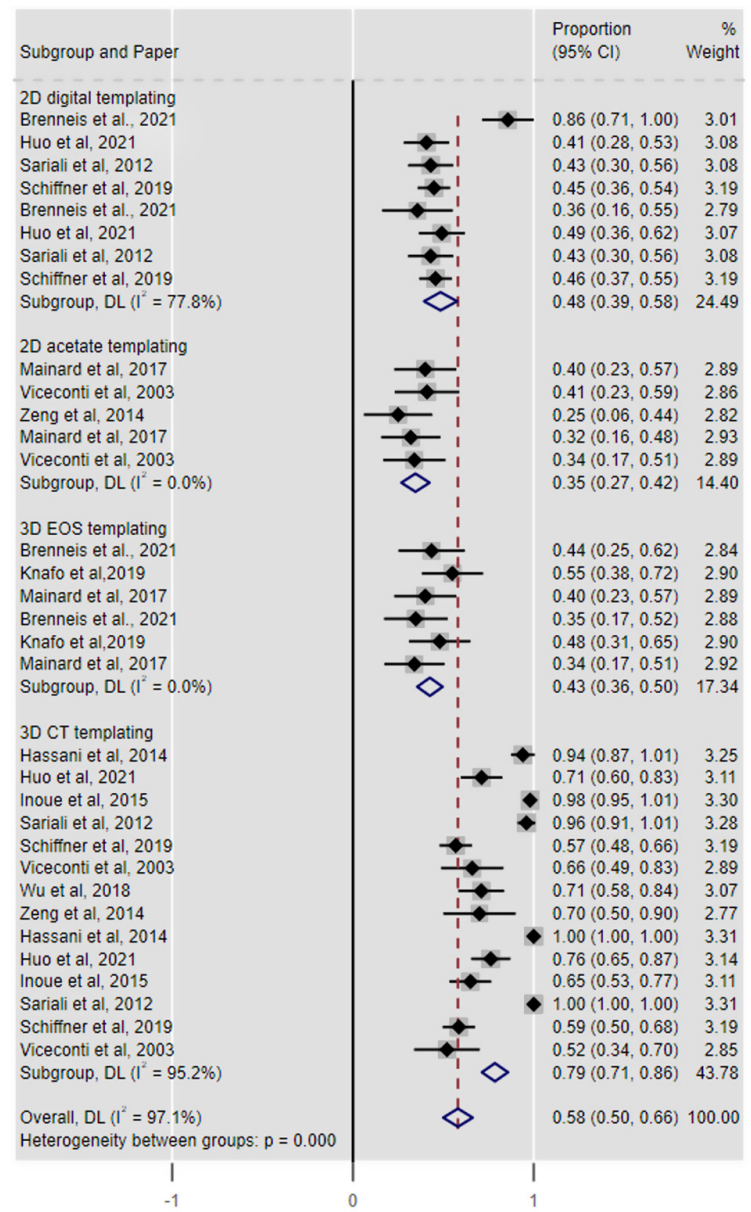

Figure 2

Forest plot comparing exact implant size prediction using 2D and $3 \mathrm{D}$ templating methods. hip arthroplasty. Spinal deformity and abnormal pelvic mobility have been associated with an increased risk of instability, dislocation and revision (32), and as such, patients with suspected spino-pelvic mobility pathology should be identified prior to performing THA and have a comprehensive radiographic examination, which should include a weight-bearing AP pelvic view as well as sitting and standing lateral projections (33), which would not be possible using CT-based 3D templating.

EOS-based 3D templating has been offered as a potential solution to this issue, using biplanar radiographs taken in the standing weight-bearing position to create

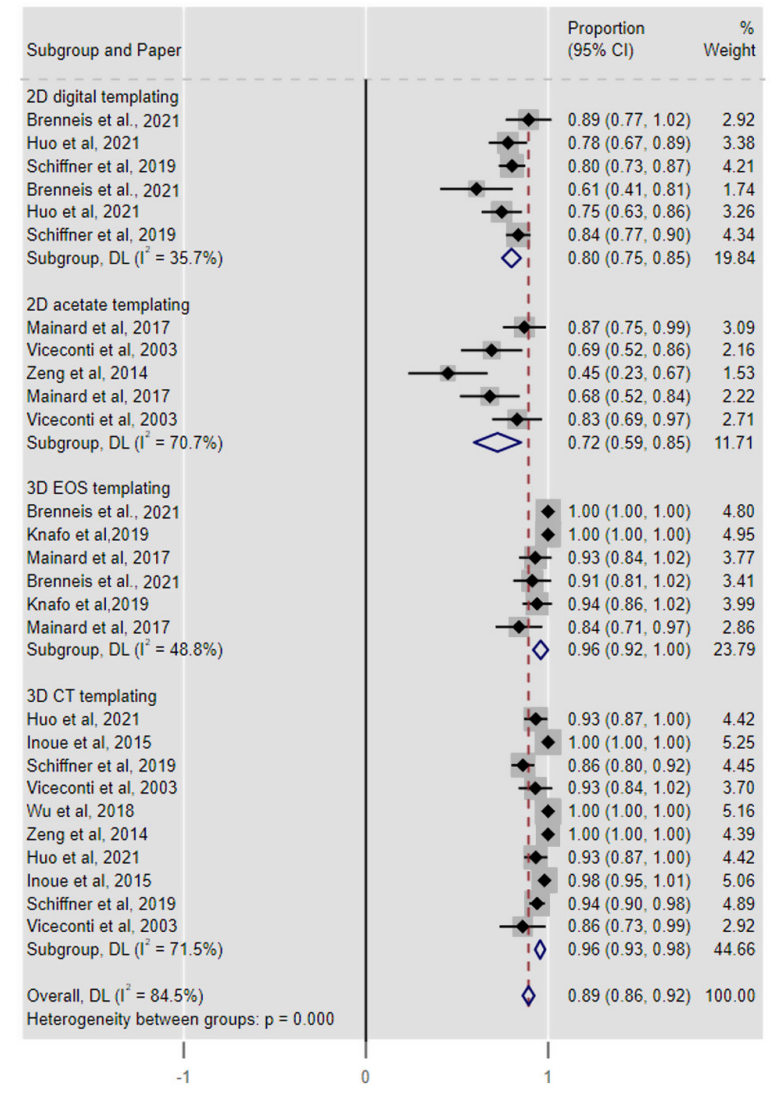

\section{Figure 3}

Forest plot comparing implant size prediction within one size using $2 \mathrm{D}$ and $3 \mathrm{D}$ templating methods. 


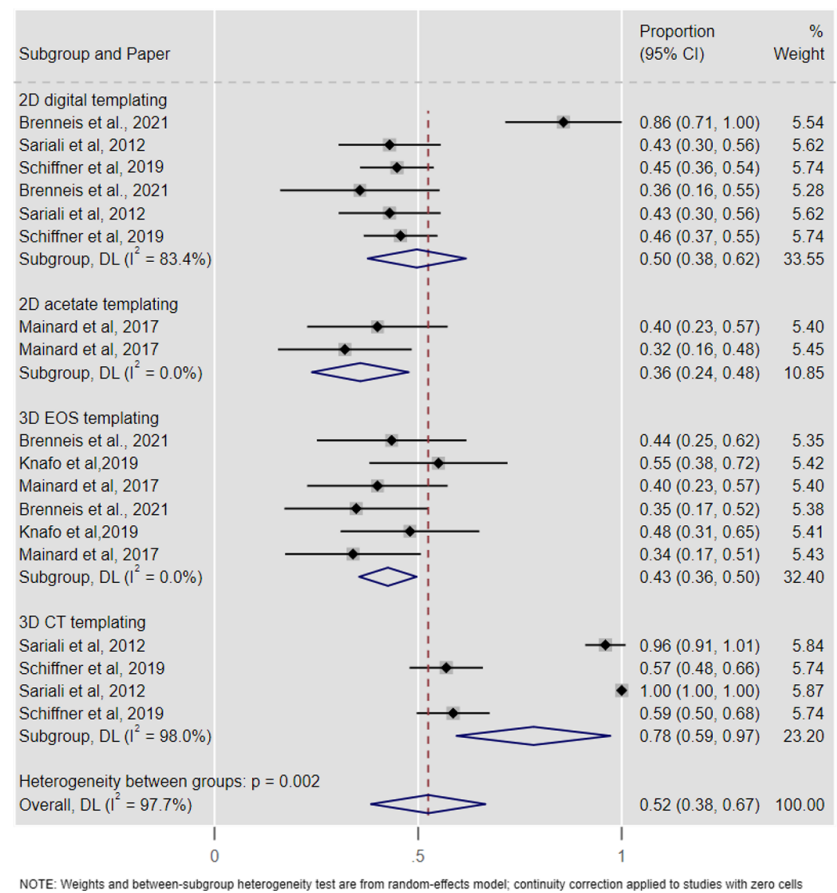

\section{Figure 4}

Forest plot comparing exact implant size prediction using 2D and 3D templating methods (simple cases).

a 3D reconstruction using sterEOS software. The result is a $3 \mathrm{D}$ image of the pelvis acquired with less exposure to ionizing radiation than a CT scan. In theory, this offers

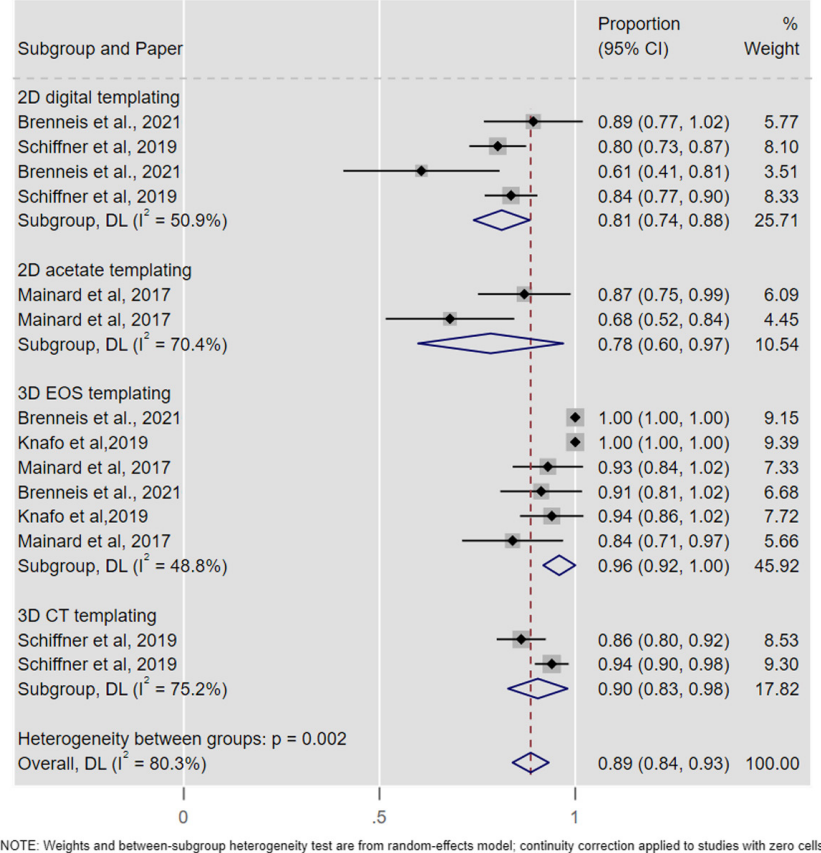

\section{Figure 5}

Forest plot comparing implant size prediction within one size using 2D and 3D templating methods (simple cases).

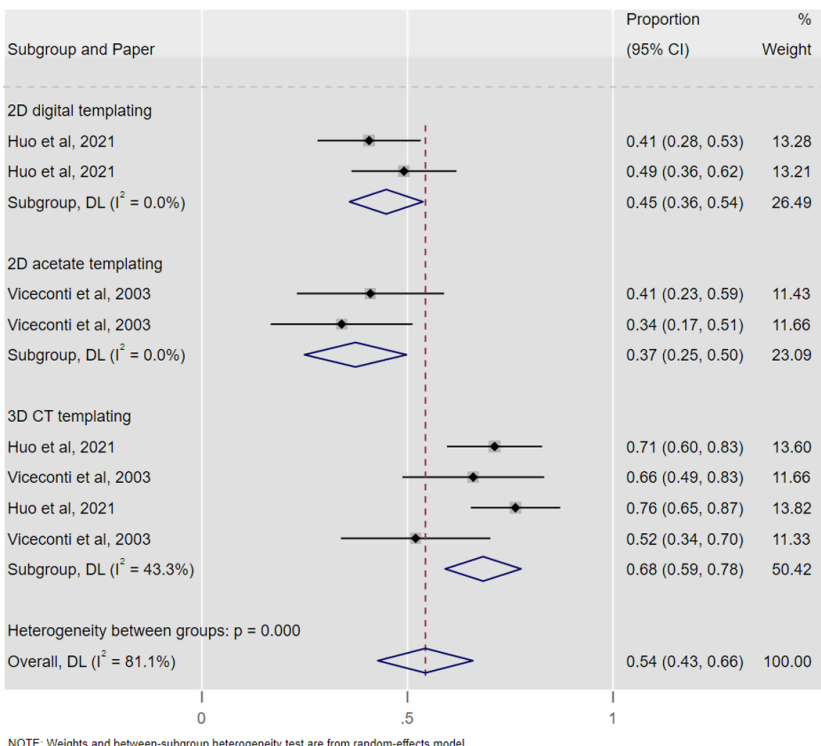

\section{Figure 6}

Forest plot comparing exact implant size prediction using 2D and 3D templating methods (mixed cases).

the 'best of both worlds' - the increased accuracy of 3D templating, whilst retaining the positional information offered by 2D templating. EOS software is relatively new and its application in orthopaedic practice has not yet been fully explored. After conducting a thorough search of the literature, only three studies $(12,21,22)$ were found which directly compared the accuracy of implant size

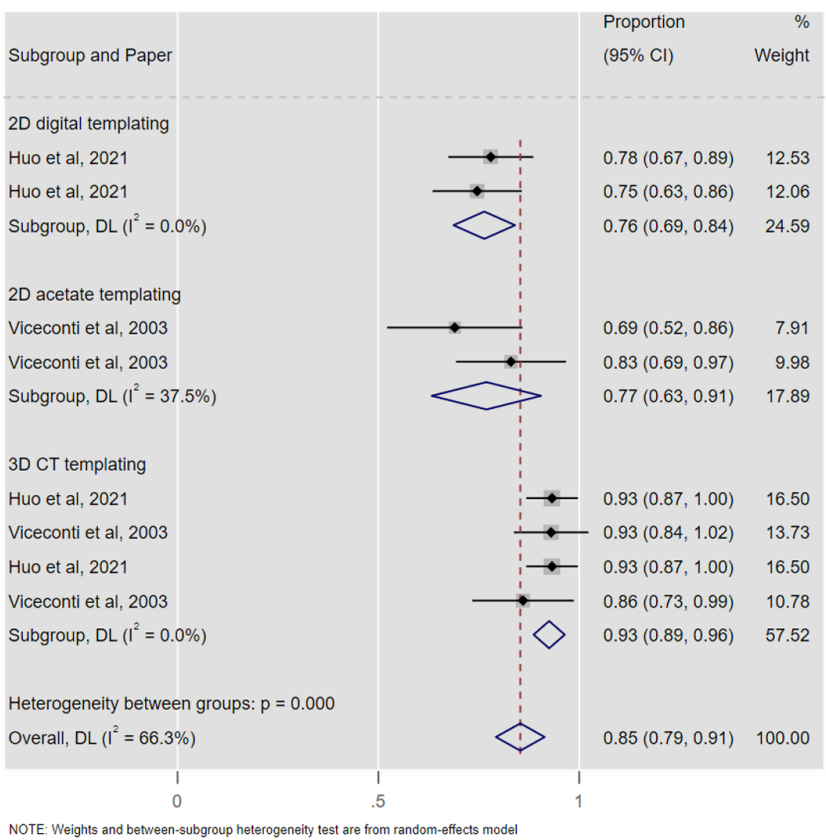

Figure 7

Forest plot comparing implant size prediction within one size using 2D and 3D templating methods (mixed cases). 


\section{E F o R T open revlews}

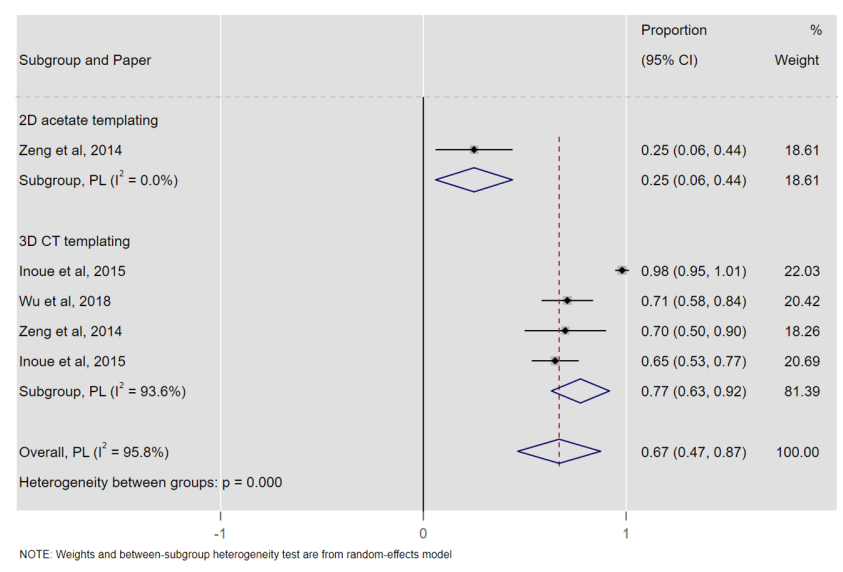

\section{Figure 8}

Forest plot comparing exact implant size prediction using 2D and 3D templating methods (complex cases).

prediction in EOS 3D templating with a conventional 2D form of templating, one of which was a pilot study (22). This pilot study found that 3D planning predicted stem sizes significantly more accurately than 2D templating within one size $(p=0.04) ; 3 D$ planning predicted cup sizes more accurately than 2D templating within one size but the difference was not statistically significant $(p=0.30)$. Therefore, whilst EOS 3D templating may be a promising technique, a lot more research is needed before its role in total hip arthroplasty planning can be confidently determined.

\section{Limitations}

There are several limitations to this systematic review. As this is an assimilation of all of the current evidence in this area, the limitations of the included studies are also

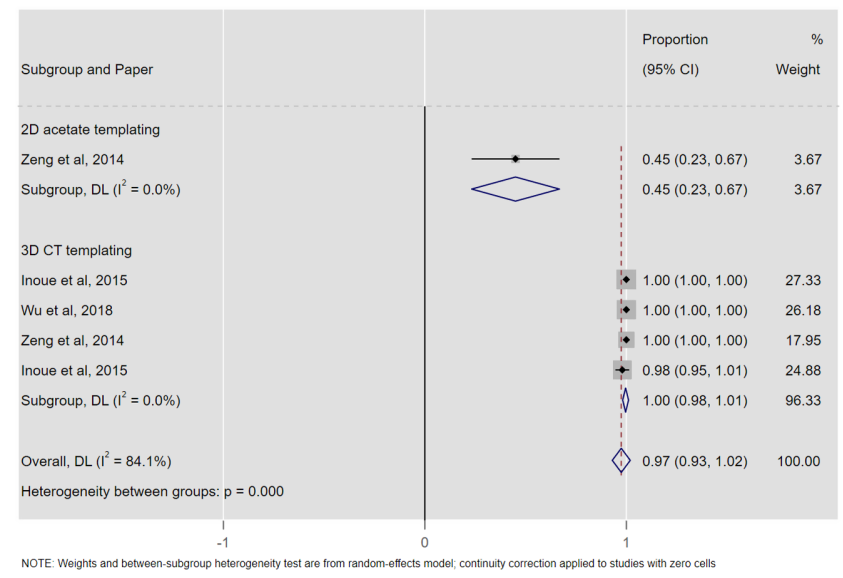

\section{Figure 9}

Forest plot comparing implant size prediction within one size using 2D and 3D templating methods (complex cases). apparent in this review. Furthermore, within this systematic review, there were only two randomized controlled trials (RCTs) $(12,23)$.

Although all of the implants used in this review were uncemented, only Inoue et al. (20) commented on the Dorr classification of the hips involved. They found that cases in which a different stem size from that determined in preoperative planning was selected were almost all Dorr type A or C. They found that in Dorr type A cases there was a tendency to select a smaller size of stem in order to prevent femoral diaphyseal fractures, while in Dorr type $C$ cases the tendency was to select a larger stem size so as to prevent rotational instability. The apparent impact of Dorr classification on stem size prediction suggests that its effects, along with the effects of body mass index (BMI) and gender, on implant size prediction should be considered in any future studies.

Finally, within this study, at least four different templating methods (EOS 3D, CT 3D, 2D digital and 2D acetate) were used for preoperative planning, and the patients included had a range of different preoperative diagnoses. The heterogeneity of the cohorts studied makes it difficult to offer a universal recommendation on the future of $3 \mathrm{D}$ templating as it relates to current 2D templating methods.

\section{Conclusion}

Despite the increased accuracy associated with 3D templating, there is not yet sufficient evidence to suggest that using 3D templating has any benefit on clinical outcomes. One of the main reasons for this is that increased accuracy in size prediction does not, per se, optimize the position and orientation of implant components. Furthermore, the multifactorial nature of how good outcomes are achieved in total hip arthroplasty means that the clinical benefit solely attributable to the use of 3D templating is something that is difficult to quantify.

More evidence regarding the effect of the increased accuracy of 3D templating is therefore needed to justify its widespread use for planning primary THA, and longterm clinical studies of large patient numbers would be required to ascertain whether this increased accuracy is of clinical relevance. Until this information is available, it is reasonable that 2D templating should remain the standard for non-complex primary total hip arthroplasty, whilst 3D templating is reserved for more complex cases with acetabular or femoral deformities where a greater appreciation of the 3D structure of the hip is required.

\section{ICMJE Conflict of Interest Statement}

The authors declare that there is no conflict of interest that could be perceived as prejudicing the impartiality of this review. 


\section{E F O R T open revieus}

\section{Funding Statement}

This work did not receive any specific grant from any funding agency in the public, commercial, or not-for-profit sector.

\section{References}

1. Mellon SJ, Liddle AD \& Pandit H. Hip replacement: landmark surgery in modern medical history. Maturitas 201375 221-226. (https://doi.org/10.1016/j. maturitas.2013.04.011)

2. Colombi A, Schena $\mathbf{D}$ \& Castelli CC. Total hip arthroplasty planning. EFORT Open Reviews 20194 626-632. (https://doi.org/10.1302/2058-5241.4.180075)

3. Machin J, Shivji F, Manktelow A \& Briggs T. Getting it right first time: best practice for hip arthroplasty surgery documentation, 2019. (available at: https://www.boa.ac.uk/ resources/best-practice-hip-arthroplasty.html).

4. Kearney R, Shaikh AH \& O'Byrne JM. The accuracy and inter-observer reliability of acetate templating in total hip arthroplasty. Irish Journal of Medical Science $2013 \mathbf{1 8 2}$ 409-414. (https://doi.org/10.1007/s11845-013-0901-6)

5. Haddad FS, Masri BA, Garbuz DS \& Duncan CP. The prevention of periprosthetic fractures in total hip and knee arthroplasty. Orthopedic Clinics of North America $1999 \mathbf{3 0}$ 191-207. (https://doi.org/10.1016/s0030-5898(05)70074-2)

6. Vigdorchik JM, Sharma AK, Jerabek SA, Mayman DJ \& Sculco PK. Templating for total hip arthroplasty in the modern age. Journal of the American Academy of Orthopaedic Surgeons 202129 e208-e216. (https://doi.org/10.5435/JAAOS-D-20-00693)

7. Shaikh AH. Preoperative planning of total hip arthroplasty. In Total Hip Replacement: An Overview. Ed. V Bagaria. London: Intech0pen, 2018

8. LecerfG, Fessy MH, Philippot R, Massin P, Giraud F, Flecher X, Girard J, MertI P, Marchetti E \& Stindel E. Femoral offset: anatomical concept, definition, assessment, implications for preoperative templating and hip arthroplasty. Orthopaedics and Traumatology, Surgery and Research 200995 210-219. (https://doi.org/10.1016/j.otsr.2009.03.010)

9. Shah N \& Hodgkinson J. Why do orthopaedic surgeons get sued after total hip replacement? Bone and Joint 36020143 42-45. (https://doi.org/10.1302/20480105.31.360214)

10. Schiffner E, Latz D, Jungbluth P, Grassmann JP, Tanner S, Karbowski A, Windolf J \& Schneppendahl J. Is computerised 3D templating more accurate than 2D templating to predict size of components in primary total hip arthroplasty? Hip International 201929 270-275. (https://doi.org/10.1177/1120700018776311)

11. Iorio R, Siegel J, Specht LM, Tilzey JF, Hartman A \& Healy WL. A comparison of acetate vs digital templating for preoperative planning of total hip arthroplasty: is digital templating accurate and safe? Journal of Arthroplasty 200924 175-179. (https://doi. org/10.1016/j.arth.2007.11.019)

12. Brenneis M, Braun S, van Drongelen S, Fey B, Tarhan T, Stief F \& Meurer A. Accuracy of preoperative templating in total hip arthroplasty with special focus on stem morphology: a randomized comparison between common digital and three-dimensional planning using biplanar radiographs. Journal of Arthroplasty 202136 1149-1155. (https:// doi.org/10.1016/j.arth.2020.10.016)

13. OCEBM Levels of Evidence Working Group. The Oxford 2011 Levels of Evidence. Oxford: Oxford Centre for Evidence-Based Medicine, 2011. (available at: http://www.cebm.net/ index.aspx?0=5653). Accessed on 3 March 2021.

14. Slim K, Nini E, Forestier D, Kwiatkowski F, Panis Y \& Chipponi J. Methodological index for non-randomized studies (minors): development and validation of a new instrument. ANZ Journal of Surgery 200373 712-716. (https://doi.org/10.1046/ j.1445-2197.2003.02748.x

15. Critical Appraisal Skills Programme. CASP (randomised controlled trial) checklist, 2020. (available at: https://casp-uk.net/wp-content/uploads/2020/10/CASP_RCT_Checklist_ PDF_Fillable_Form.pdf)

16. Kontopantelis $\mathbf{E}$ \& Reeves $\mathbf{D}$. Performance of statistical methods for meta-analysis when true study effects are non-normally distributed: a simulation study. Statistical Methods in Medical Research 201221 409-426. (https://doi.org/10.1177/0962280210392008)

17. Fisher D, Harris R, Bradburn M, Deeks J, Harbord R, Altman D, Steichen T, Sterne J \& Higgins J. METAN: Stata Module for Fixed and Random Effects Meta-Analysis, S456798 Version. Boston, MA: Boston College Department of Economics, 2006. (available at: https://ideas.repec.org/s/boc/bocode.html). Revised on 24 February 2021.

18. Hassani H, Cherix S, Ek ET \& Rüdiger HA. Comparisons of preoperative three-dimensional planning and surgical reconstruction in primary cementless total hip arthroplasty. Journal of Arthroplasty 201429 1273-1277. (https://doi.org/10.1016/j. arth.2013.12.033)

19. Huo J, Huang G, Han D, Wang X, Bu Y, Chen Y, Cai D \& Zhao C. Value of $3 D$ preoperative planning for primary total hip arthroplasty based on artificial intelligence technology. Journal of Orthopaedic Surgery and Research 202116 156. (https://doi. org/10.1186/s13018-021-02294-9)

20. Inoue D, Kabata T, Maeda T, Kajino Y, Fujita K, Hasegawa K, Yamamoto T \& Tsuchiya H. Value of computed tomography-based three-dimensional surgical preoperative planning software in total hip arthroplasty with developmental dysplasia of the hip. Journal of Orthopaedic Science 201520 340-346. (https://doi.org/10.1007/s00776-014-0683-3)

21. Knafo Y, Houfani F, Zaharia B, Egrise F, Clerc-Urmès I \& Mainard D. Value of $3 D$ preoperative planning for primary total hip arthroplasty based on biplanar weightbearing radiographs. BioMed Research International 20192019 1932191. (https:// doi.org/10.1155/2019/1932191)

22. Mainard D, Barbier 0, Knafo Y, Belleville R, Mainard-Simard L \& Gross JB. Accuracy and reproducibility of preoperative three-dimensional planning for total hip arthroplasty using biplanar low-dose radiographs: a pilot study. Orthopaedics and Traumatology, Surgery and Research 2017103 531-536. (https://doi.org/10.1016/j.otsr.2017.03.001)

23. Sariali E, Mauprivez R, Khiami F, Pascal-Mousselard H \& Catonné Y Accuracy of the preoperative planning for cementless total hip arthroplasty: a randomised comparison between three-dimensional computerised planning and conventional templating. Orthopaedics and Traumatology, Surgery and Research 201298 151-158. (https://doi.org/10.1016/j.otsr.2011.09.023)

24. Viceconti M, Lattanzi R, Antonietti B, Paderni S, Olmi R, Sudanese A \& Toni A. CT-based surgical planning software improves the accuracy of total hip replacement preoperative planning. Medical Engineering and Physics 200325 371-377. (https://doi. org/10.1016/s1350-4533(03)00018-3)

25. Wako Y, Nakamura J, Miura M, Kawarai Y, Sugano M \& Nawata K Interobserver and intraobserver reliability of three-dimensional preoperative planning software in total hip arthroplasty. Journal of Arthroplasty 201833 601-607. (https://doi. org/10.1016/j.arth.2017.08.031)

26. Wu P, Liu Q, Fu M, Zhang Z, He S, Liao W \& Kang Y. Value of computed tomography-based three-dimensional pre-operative planning in cup placement in total hip arthroplasty with dysplastic acetabulum. Journal of Investigative Surgery 201932 607-613. (https://doi.org/10.1080/08941939.2018.1444828)

27. Zeng Y, Lai OJ, Shen B, Yang J, Zhou ZK, Kang PD, Pei FX \& Zhou X. Threedimensional computerized preoperative planning of total hip arthroplasty with high-riding 


\section{E F O R T open revieus}

dislocation developmental dysplasia of the hip. Orthopaedic Surgery 20146 95-102. (https://doi.org/10.1111/0s.12099)

\section{Huppertz A, Radmer S, Wagner M, Roessler T, Hamm B \& Sparmann M.} Computed tomography for preoperative planning in total hip arthroplasty: what radiologists need to know. Skeletal Radiology 201443 1041-1051. (https://doi.org/10.1007/s00256014-1853-2)

29. Geijer M, Rundgren G, Weber L \& Flivik G. Effective dose in low-dose CT compared with radiography for templating of total hip arthroplasty. Acta Radiologica 2017 58 1276-1282. (https://doi.org/10.1177/0284185117693462)

30. Huppertz A, Radmer S, Asbach P, Juran R, Schwenke C, Diederichs G, Hamm B \& Sparmann M. Computed tomography for preoperative planning in minimal-invasive total hip arthroplasty: radiation exposure and cost analysis.
European Journal of Radiology 201178 406-413. (https://doi.org/10.1016/j. ejrad.2009.11.024)

31. Rivière C, Lazic S, Dagneaux L, Van Der Straeten C, Cobb J \& MuirheadAllwood S. Spine-hip relations in patients with hip osteoarthritis. EFORT Open Reviews 20183 39-44. (https://doi.org/10.1302/2058-5241.3.170020)

32. Mancino F, Cacciola G, Di Matteo V, Perna A, Proietti L, Greenberg A, Ma M, Sculco PK, Maccauro G \& De Martino I. Surgical implications of the hipspine relationship in total hip arthroplasty. Orthopedic Reviews 202012 8656. (https://doi. org/10.4081/or.2020.8656)

33. Haffer H, Adl Amini D, Perka C \& Pumberger M. The impact of spinopelvic mobility on arthroplasty: implications for hip and spine surgeons. Journal of Clinical Medicine 20209 2569. (https://doi.org/10.3390/jcm9082569) 